\title{
Effectiveness of inhaler types for real-world asthma management: retrospective observational study using the GPRD
}

This article was published in the following Dove Press journal:

Journal of Asthma and Allergy

22 April 2011

Number of times this article has been viewed

\author{
David Price ${ }^{1,2}$ \\ John Haughney' \\ Erika Sims ${ }^{2}$ \\ Muzammil Ali ${ }^{2}$ \\ Julie von Ziegenweidt ${ }^{2}$ \\ Elizabeth $\vee$ Hillyer ${ }^{2}$ \\ Amanda J Lee ${ }^{3}$ \\ Alison Chisholm ${ }^{2}$ \\ Neil Barnes ${ }^{4}$ \\ 'Centre of Academic Primary Care, \\ University of Aberdeen, Aberdeen, UK; \\ ${ }^{2}$ Research in Real Life Ltd, Cawston, \\ Norwich, UK; ${ }^{3}$ Section of Population \\ Health, University of Aberdeen, UK; \\ ${ }^{4}$ Department of Respiratory Medicine, \\ London Chest Hospital, Barts and The \\ London NHS Trust, London, UK
}

Correspondence: David Price

Centre of Academic Primary Care, University of Aberdeen, Foresterhill Health Centre, Westburn Road, Aberdeen AB25 2AY, Scotland, UK Tel +44 I 224554588

Fax +44 I224 550683

Email david@respiratoryresearch.org
Purpose: Results of randomized controlled trials may not predict effectiveness of inhaled corticosteroids (ICS) in real-world clinical practice, where inhaler technique and device characteristics can influence effectiveness. We compared asthma outcomes for ICS delivered via three different inhaler devices: pressurized metered-dose inhaler (pMDI), breath-actuated MDI (BAI), and dry powder inhaler (DPI).

Patients and methods: This retrospective database study evaluated 1-year outcomes for primary care patients with asthma aged 5-60 years prescribed their first ICS (initiation population) by pMDI $(n=39,746)$, BAI $(n=9809)$, or DPI $(n=6792)$, or their first ICS dose increase (step-up population) by pMDI $(n=6245)$, BAI $(n=1388)$, or DPI $(n=1536)$. Co-primary outcome measures were composite proxy measures of asthma control (no hospital attendance for asthma, oral corticosteroids, or antibiotics for lower respiratory infection) and severe exacerbations (unscheduled hospital admission, emergency room attendance, or oral corticosteroids). Outcomes were adjusted for potential confounding factors identified during a baseline year.

Results: In the initiation population, adjusted odds ratios (95\% confidence intervals [CI]) for asthma control, as compared with pMDIs, were significantly better for BAIs (1.08 [1.02-1.14]) and DPIs (1.13 [1.06-1.21]), while adjusted exacerbation rate ratios (95\% CI) were $1.00(0.93-1.08)$ and $0.88(0.81-0.95)$, respectively. In the step-up population, adjusted odds of asthma control were $1.21(1.05-1.39)$ for BAIs and $1.13(0.99-1.29)$ for DPIs; adjusted exacerbation rate ratios were $0.83(0.71-0.98)$ for BAIs and $0.85(0.74-0.98)$ for DPIs, compared with pMDIs.

Conclusion: Inhaler device selection may have a bearing on clinical outcomes. Differences in real-world effectiveness among these devices require closer evaluation in well-designed prospective trials.

Keywords: asthma control, dry powder inhaler, breath-actuated inhaler, metered-dose inhaler, primary care

\section{Introduction}

The findings of randomized controlled trials (RCTs) are integral to establishing the efficacy of therapies but may not predict their effectiveness in a real-world clinical setting, because RCTs are designed to maximize internal validity. Therefore, strict RCT inclusion criteria typically select idealized patient populations, free of comorbidities and with good adherence, and RCT protocols tend to require close patient monitoring at a level rarely possible or achieved in everyday clinical practice. Over $90 \%$ of patients with asthma in the community, such as those who smoke or have limited airway reversibility, do not meet eligibility criteria for most RCTs of asthma therapies. ${ }^{1,2}$

Several authors have expressed concern about the limited external validity, or generalizability, of many $\mathrm{RCTs},{ }^{1-5}$ and there remains a need for effectiveness data to 
complement RCT findings. The use of diverse approaches to determine the appropriate use of therapeutic interventions is advocated by Rawlins ${ }^{5}$ to replace an evidence hierarchy placing RCT results at the pinnacle of importance. Rigorously conducted observational studies can provide evidence to supplement that from RCTs.

Real-life data is particularly pertinent for inhaled therapies, for which additional factors such as delivery device characteristics and inhaler technique come into play and can influence the effectiveness of therapy. ${ }^{6}$ Reviews of RCTs comparing asthma inhaler devices report no significant differences in clinical effectiveness according to device type. ${ }^{7-9}$ However, patients enrolled in these trials usually received inhaler training and had to demonstrate and maintain proper inhaler technique throughout the trials. Yet in the real world, patients frequently make mistakes when using their inhaler devices, ${ }^{6,10-13}$ and errors in use of corticosteroid inhalers have been associated with poor asthma control. ${ }^{14}$ Moreover, most inhaler RCTs are short term, and there is some evidence that, in the real world, inhaler technique deteriorates over time. ${ }^{6}$ Indeed, results of an earlier observational study using a large primary care medical record database suggest that inhaler device choice does in fact affect asthma outcomes. ${ }^{15}$

The objective of this retrospective database study was to compare outcomes for patients with asthma who were prescribed their first inhaled corticosteroid (ICS) therapy or an increase in ICS dose via pressurized metered-dose inhaler (pMDI), breath-actuated MDI (BAI), or dry powder inhaler (DPI). We examined respiratory-related clinical endpoints combined in composite measures of asthma control and exacerbations.

\section{Methods}

This 2-year retrospective observational study comprised a baseline year for defining cohorts and potential confounding factors, followed consecutively by an outcome year starting on the index date when patients received a prescription for first ICS or an increase in dose of ICS. The data source for the study was the General Practice Research Database (GPRD), a large computerized database containing de-identified longitudinal medical record data from over 450 participating general practices located throughout the United Kingdom (UK), including England, Scotland, Wales, and Northern Ireland. ${ }^{16}$ The GPRD is well-validated and has been used frequently for respiratory research. ${ }^{17-20}$

Medical records from the GPRD were examined for a 10.5-year period when all inhaler devices of interest were available, beginning January 1997 and ending June 30, 2007.
Patients with asthma and aged 5-60 years on the index date were included in the study if they were continuously registered at the same practice for at least 2 years including the 12 months before and 12 months after the index date; and the practice had to be judged by the GPRD as having up-to-standard data during that time. ${ }^{16}$ Evidence of asthma was defined as a recorded diagnosis of asthma or two or more prescriptions for ICS for asthma at more than one time point during the outcome year. Prescribing information recorded in the GPRD includes dosage, quantity, indication, and instructions. Patients were excluded if their record contained a diagnostic code for chronic obstructive pulmonary disease or any chronic respiratory condition other than asthma or if they were prescribed more than one ICS or a combination inhaler with long-acting $\beta 2$ agonist (LABA) on the index date.

Two separate analyses were undertaken for 1) those patients receiving a first ICS prescription (initiation population) and 2) those receiving an increased dose of ICS (step-up population), the latter having at least one recorded prescription for ICS during the baseline year. Patients were included if they received ICS using only one device type, namely, a pMDI, BAI, or DPI, during the outcome year. Cost effectiveness analyses were also carried out for both the initiation and step-up populations, but these data are not the focus of this paper and are published separately. ${ }^{21}$

The GPRD Independent Scientific Advisory Committee approved the use of GPRD data for this study.

\section{Outcome measures}

All outcomes were predefined before reviewing the data. The two co-primary outcome measures were a proxy for asthma control and severe exacerbation rate. The "primary measure of asthma control" was a composite endpoint, defined as including all of the following:

1. no recorded hospital attendance for asthma (neither admission nor attendance at the emergency department, the outpatient department, or out of hours);

2. no prescription for oral corticosteroids (acute or maintenance); and

3. no consultations, hospital admissions, or emergency department attendance for lower respiratory tract infection requiring antibiotics.

A severe asthma exacerbation was defined, in line with a recent ATS/ERS task force definition, ${ }^{22}$ as unscheduled hospital admission or emergency department attendance for respiratory disease or a prescription for oral corticosteroids. Exacerbations on the index date were included within the outcome data. 
Secondary outcomes included another composite measure, "asthma control plus short-acting $\beta 2$ agonist (SABA) use", which factored the additional criterion of minimal reliever medication use into the co-primary control proxy (ie, control required a maximum average daily use of $200 \mu \mathrm{g}$ albuterol or $500 \mu \mathrm{g}$ terbutaline). Other secondary endpoints were the disaggregated outcomes comprising the composite measures and changes in therapy, including increase in ICS dose or use of additional therapy.

The ICS doses are reported ex-valve as the chlorofluorocarbonbeclomethasone (CFC-BDP)-equivalent, with doses of budesonide (BUD), fluticasone propionate (FP), BDP in solution (Qvar ${ }^{\circledR}$, Teva UK), and mometasone (MOM) converted as necessary in the following dose ratios relative to CFC-BDP: CFC-BDP:BUD:FP:Qvar:MOM = 1:1:2:2:2.

\section{Statistical analyses}

Descriptive statistics were used to compare baseline factors among cohorts. The Kruskal-Wallis test was used to compare skewed continuous data between cohorts whilst the $\chi^{2}$ test was used to compare categorical factors.

Patients prescribed pMDIs were defined as the reference cohort, and patients prescribed BAIs or DPIs as the comparison cohorts. Results were examined separately for each population (initiation and step-up populations) during the outcome year, the primary period of analysis. All analyses were specified a priori.

Odds ratios for the dichotomized definitions of asthma control were calculated using a binary logistic regression model with control as the dependent variable and cohort, together with potential confounding factors (year of index date, age, sex, socioeconomic status, and comorbidity and treatment with medication that could affect respiratory outcomes), as explanatory variables. Socioeconomic status was that assigned, in quintiles, by the GPRD to each practice using the Index of Multiple Deprivation as a proxy measure. The GPRD has linked the socioeconomic status to small areas using the practice postcode where possible. Comorbidities were included via the Charlson comorbidity index score, ${ }^{23}$ a weighted index that accounts for number and severity of comorbidities, as calculated for each patient using ICD-9 matching algorithms produced by CliniClue software (http://www.cliniclue.com/software).

The selected confounding factors were variables that were significantly different $(P<0.10)$ between cohorts at baseline.

The total number of severe exacerbations in the outcome period was compared between cohorts using a Poisson regression model to obtain estimates of exacerbation rates relative to the pMDI cohort. The model was adjusted for over-dispersion using robust standard errors and adjustments for potential baseline confounders.

Data were analyzed using SPSS version 17 (SPSS, Chicago, IL, USA), and differences between cohorts were considered to be significant if $P<0.05$ and trends if $0.05 \leq P<0.10$.

\section{Results}

Figure 1 depicts the identification of eligible patients in the GPRD who received a first prescription for ICS or increased dose of ICS. Baseline characteristics and asthma-related medical resource use of patients in the three cohorts of the initiation and step-up populations are summarized in Tables 1 and 2 .

\section{Patients receiving a first prescription for ICS: initiation population}

There were several statistically significant but small baseline differences among the three cohorts (Tables 1 and 2). Given the minimal clinical significance of these differences, as adjudicated by clinicians in the research team, these factors were handled through statistical modeling, which allowed adjustment of outcomes for potential confounding factors rather than necessitating subgroup or matched analysis.

The dose of ICS prescribed at the index date was significantly different among the three cohorts, with the same median dose in all three $(400 \mu \mathrm{g} /$ day $)$, and wider variability in the BAI and DPI cohorts (Table 3). Spacers were prescribed to $17.7 \%, 4.0 \%$, and $0.7 \%$ of patients in pMDI, BAI, and DPI cohorts, respectively. A statistically significant, but clinically small, difference in ICS dose as received (based on prescriptions dispensed over the 12-month period) was also evident during the outcome year (see Table 3). Thus, the profile of dosing across the treatment cohorts was fairly similar in terms of actual use, with some differences in proportions of patients prescribed the lowest starting doses.

The adjusted odds ratios for asthma control during the outcome year were significantly greater for patients prescribed a BAI or DPI relative to those prescribed a pMDI (Figure 2). The adjusted rate ratio for severe exacerbations was significantly lower in the DPI, but not the BAI, cohort, relative to the pMDI cohort (Figure 2).

When restricted SABA use was added to the composite measure, the odds ratios for asthma control plus SABA use significantly favored patients in BAI and DPI cohorts 


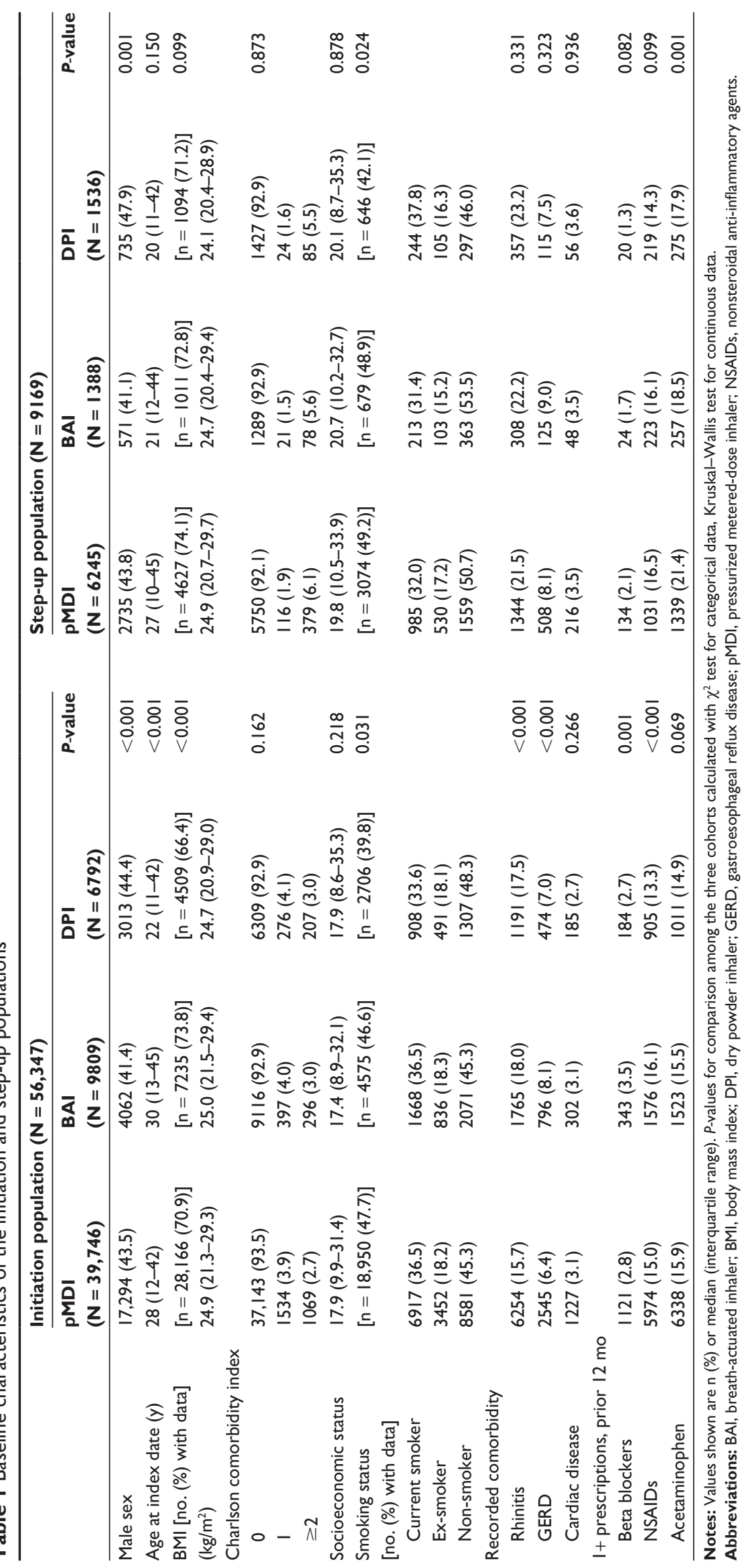




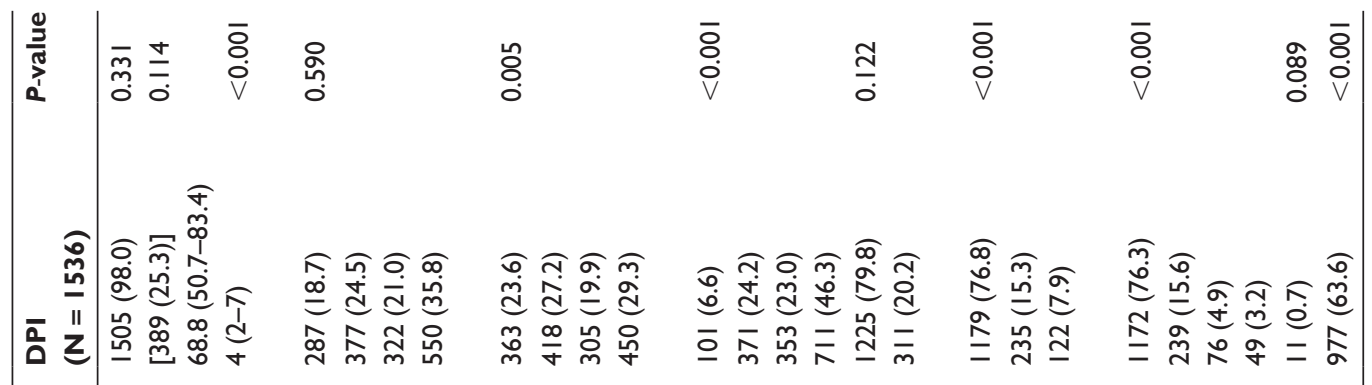

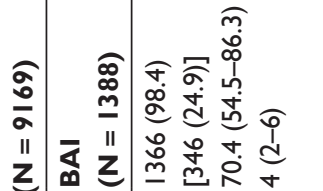

ใ.

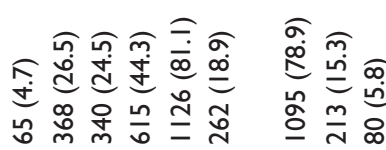

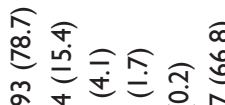
$\underset{\sim}{\infty} \frac{\sim}{m} \frac{\infty}{m} \stackrel{\infty}{\stackrel{\infty}{y}}$

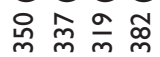

ब. $\widehat{m} \widehat{\infty}$ क

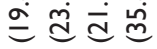

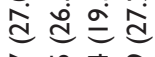

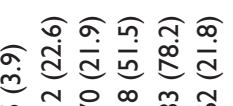

Ki

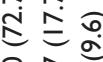

กิธ

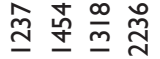

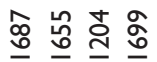

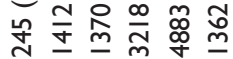

亭全觉

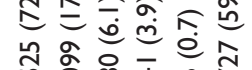

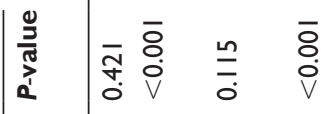

ò

$\bar{o}$

oิ

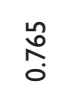

落商

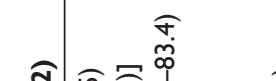

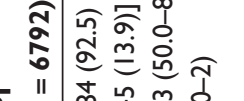

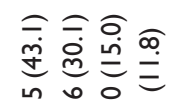

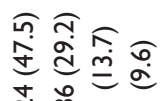

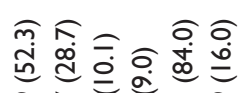

क्षे

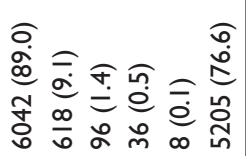

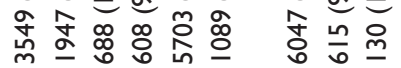

ชิ

K.ำ

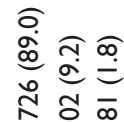

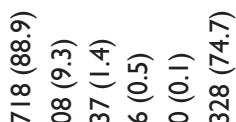

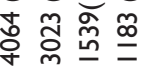

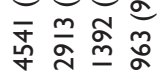

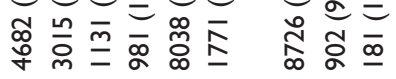

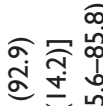

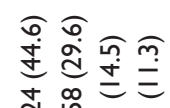

กิธ

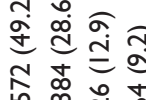

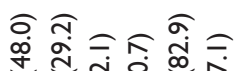

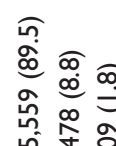

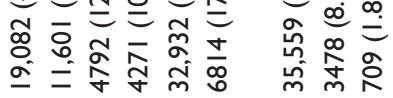
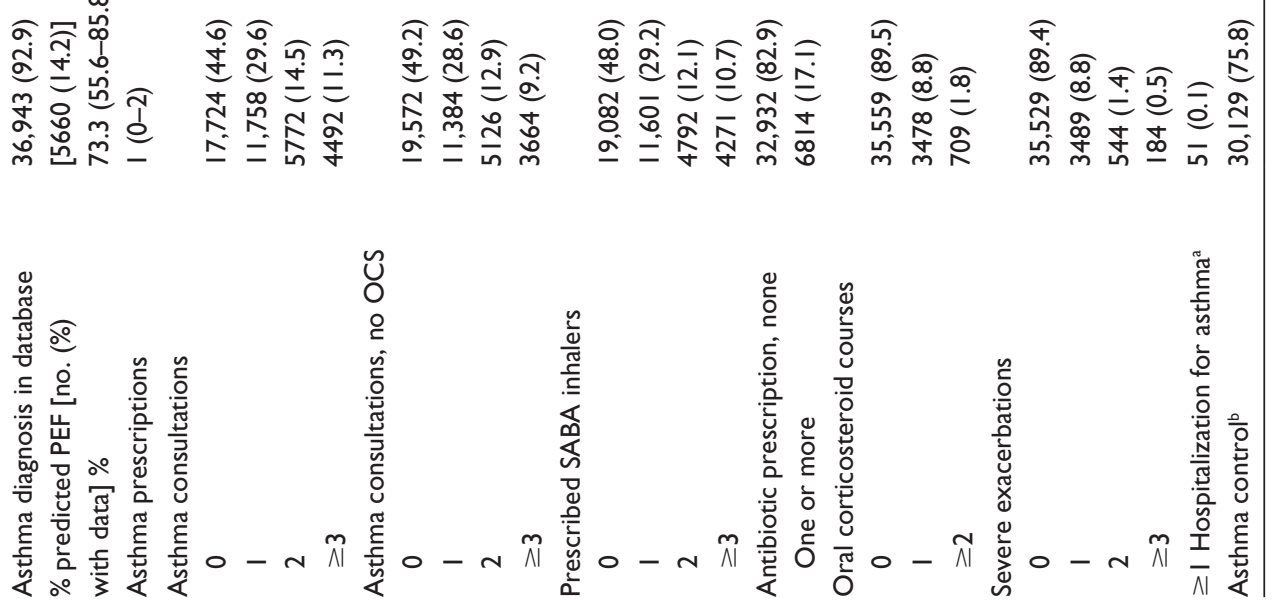
Table 3 Inhaled corticosteroid type and doses prescribed for and used by patients receiving a first prescription or increased dose of ICS

\begin{tabular}{|c|c|c|c|c|}
\hline & \multicolumn{4}{|c|}{ Initiation population $(\mathbf{N}=56,347)$} \\
\hline & $\begin{array}{l}\text { pMDI } \\
(N=39,746)\end{array}$ & $\begin{array}{l}\text { BAI } \\
(\mathrm{N}=9809)\end{array}$ & $\begin{array}{l}\text { DPI } \\
(N=6792)\end{array}$ & $P$-value \\
\hline \multicolumn{5}{|c|}{ ICS prescribed at the index date } \\
\hline Beclomethasone $\mathrm{e}^{\mathrm{a}}$ & $33,926(85.4)$ & $8750(89.2)$ & $1468(21.6)$ & - \\
\hline Qvar & $2938(7.4)$ & $1059(10.8)$ & $0(0)$ & \\
\hline Fluticasone & $1473(3.7)$ & $0(0)$ & $788(11.6)$ & \\
\hline Mometasone & $0(0)$ & $0(0)$ & $39(0.6)$ & \\
\hline Budesonide & $1380(3.5)$ & $0(0)$ & $4497(66.2)$ & \\
\hline Ciclesonide & $29(0.1)$ & $0(0)$ & $0(0)$ & \\
\hline \multicolumn{5}{|c|}{ ICS dose prescribed at index date } \\
\hline Median (IQR) & $400(400-400)$ & $400(200-400)$ & $400(200-800)$ & $<0.001$ \\
\hline $\mathrm{I}-200 \mu \mathrm{g} /$ day & $8223(20.7)$ & $2981(30.4)$ & $1999(29.4)$ & $<0.001$ \\
\hline $20 \mathrm{I}-400 \mu \mathrm{g} /$ day & $24,230(61.0)$ & $5366(54.7)$ & $2816(41.5)$ & \\
\hline $40 \mathrm{I}-800 \mu \mathrm{g} /$ day & $5333(13.4)$ & $94 \mid(9.6)$ & $1523(22.4)$ & \\
\hline$\geq 800 \mu \mathrm{g} /$ day & $1960(4.9)$ & $521(5.3)$ & $454(6.7)$ & \\
\hline \multicolumn{5}{|c|}{ ICS dose used over outcome year ${ }^{b}$} \\
\hline Median (IQR) & I 37 (55-274) & $142(55-274)$ & 110 (55-252) & $<0.001$ \\
\hline $\mathrm{I}-200 \mu \mathrm{g} /$ day & $24,398(61.4)$ & $5987(61.0)$ & $4602(67.8)$ & $<0.001$ \\
\hline $20 \mathrm{I}-400 \mu \mathrm{g} /$ day & $9497(23.9)$ & $2368(24.1)$ & $1318(19.4)$ & \\
\hline $40 \mathrm{I}-800 \mu \mathrm{g} /$ day & $4391(11.0)$ & $1131(11.5)$ & $673(9.9)$ & \\
\hline \multirow[t]{4}{*}{$\geq 800 \mu \mathrm{g} /$ day } & $1455(3.7)$ & $322(3.3)$ & |9| (2.8) & \\
\hline & \multicolumn{4}{|c|}{ Step-up population $(N=9169)$} \\
\hline & pMDI & BAI & DPI & $P$-value \\
\hline & $(N=6245)$ & $(N=1388)$ & $(N=1536)$ & \\
\hline \multicolumn{5}{|c|}{ ICS dose used over baseline year ${ }^{b}$} \\
\hline $\mathrm{I}-200 \mu \mathrm{g} /$ day & $4463(71.5)$ & $1042(75.1)$ & $1103(71.8)$ & 0.008 \\
\hline $20 \mathrm{I}-400 \mu \mathrm{g} /$ day & $1150(18.4)$ & $237(17.1)$ & $264(17.2)$ & \\
\hline $40 \mathrm{I}-800 \mu \mathrm{g} /$ day & $487(7.8)$ & $83(6.0)$ & $116(7.6)$ & \\
\hline$\geq 800 \mu \mathrm{g} /$ day & $145(2.3)$ & $26(1.9)$ & $53(3.5)$ & \\
\hline \multicolumn{5}{|c|}{ ICS prescribed at the index date } \\
\hline Beclomethasone ${ }^{\mathrm{a}}$ & $4499(72.0)$ & $1205(86.8)$ & $308(20.1)$ & - \\
\hline Qvar & $442(7.1)$ & $183(13.2)$ & $0(0)$ & \\
\hline Fluticasone & $1028(16.5)$ & $0(0)$ & $382(24.9)$ & \\
\hline Mometasone & $0(0)$ & $0(0)$ & $32(2.1)$ & \\
\hline Budesonide & $274(4.4)$ & $0(0)$ & $814(53.0)$ & \\
\hline Ciclesonide & $2(0)$ & $0(0)$ & $0(0)$ & \\
\hline \multicolumn{5}{|c|}{ ICS dose prescribed at index date } \\
\hline Median (IQR) & $800(400-1000)$ & $500(400-1000)$ & $800(400-1000)$ & $<0.001$ \\
\hline $\mathrm{I}-200 \mu \mathrm{g} /$ day & $221(3.5)$ & $67(4.8)$ & $64(4.2)$ & $<0.001$ \\
\hline $20 \mathrm{I}-400 \mathrm{~g} /$ day & $2068(33.1)$ & $620(44.7)$ & $469(30.5)$ & \\
\hline $40 \mathrm{I}-800 \mu \mathrm{g} /$ day & $2103(33.7)$ & $35 I(25.3)$ & $606(39.5)$ & \\
\hline$\geq 800 \mu \mathrm{g} /$ day & $1853(29.7)$ & $350(25.2)$ & $397(25.8)$ & \\
\hline \multicolumn{5}{|c|}{ ICS dose used over outcome year ${ }^{b}$} \\
\hline Median (IQR) & $329(164-658)$ & $301(164-548)$ & $274(142-548)$ & $<0.001$ \\
\hline $\mathrm{I}-200 \mu \mathrm{g} /$ day & $1700(27.2)$ & $439(31.6)$ & $575(37.5)$ & $<0.001$ \\
\hline $20 \mathrm{I}-400 \mu \mathrm{g} /$ day & I 727 (27.7) & $392(28.2)$ & $430(28.0)$ & \\
\hline $40 \mathrm{I}-800 \mu \mathrm{g} /$ day & I57| (25.2) & $365(26.3)$ & $317(20.7)$ & \\
\hline$\geq 800 \mu \mathrm{g} /$ day & $1246(20.0)$ & $192(13.8)$ & $211(13.8)$ & \\
\hline
\end{tabular}

Notes: Values shown are $\mathrm{n}(\%)$ or median (interquartile range). P-values for comparison among the three cohorts calculated with $\chi^{2}$ test for categorical data, Kruskal-Wallis test for continuous data; The ICS doses are reported as the chlorofluorocarbon-beclomethasone (CFC-BDP)-equivalent, with doses of budesonide (BUD), fluticasone propionate (FP), BDP in solution (Qvar ${ }^{\circledR}$, Teva UK), and mometasone (MOM) converted as necessary in the following dose ratios relative to CFC-BDP: CFC-BDP:BUD:FP:Qvar:

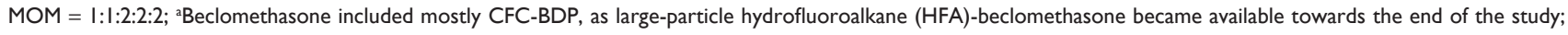
'The ICS doses used over the baseline and outcome years were calculated as the dispensed amount divided by 365 .

Abbreviations: BAI, breath-actuated inhaler; DPI, dry powder inhaler; ICS, inhaled corticosteroid; pMDI, pressurized metered-dose inhaler. 

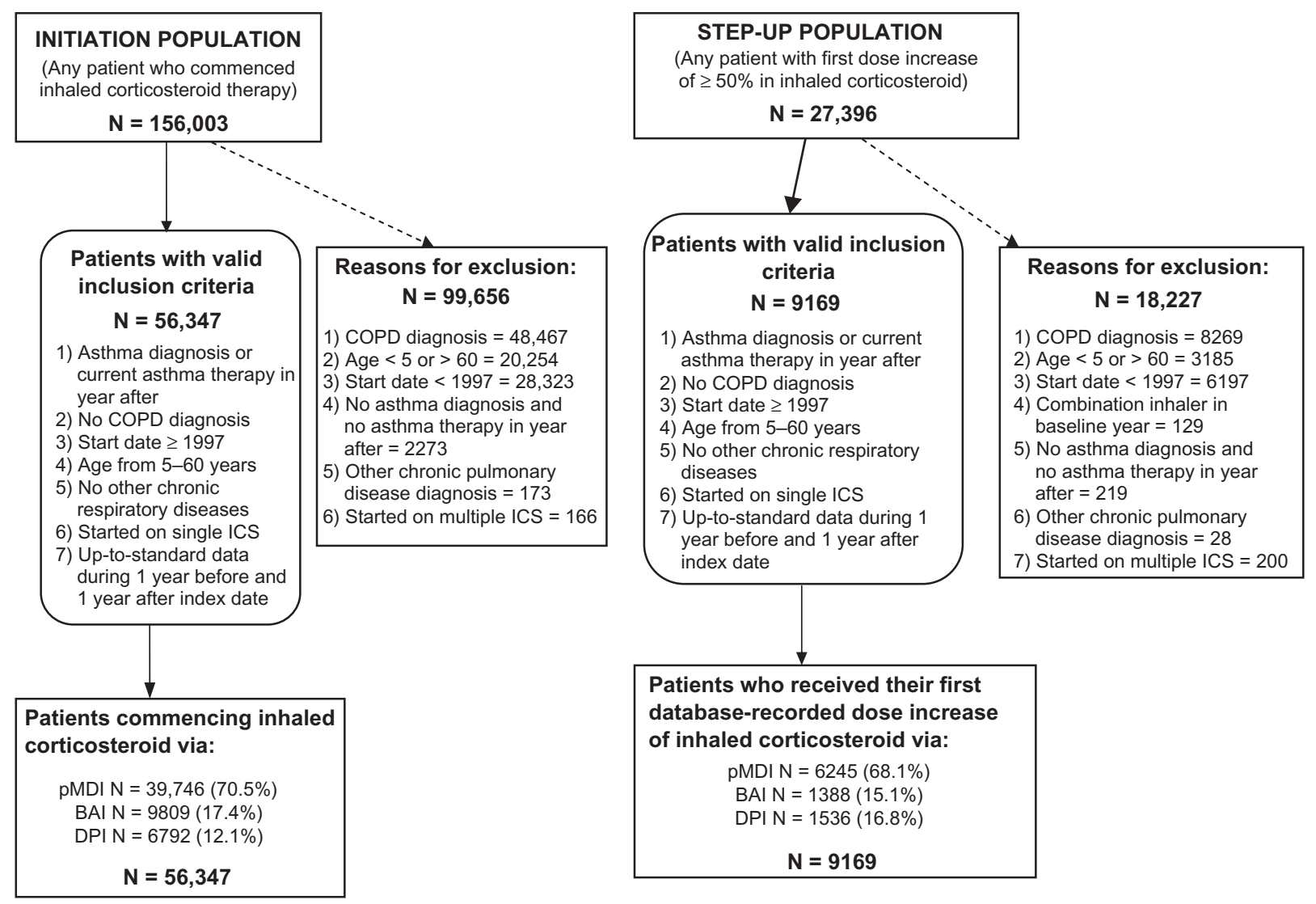

Figure I Selection of eligible patients in the database.

Abbreviations: BAI, breath-actuated inhaler; COPD, chronic obstructive pulmonary disease; DPI, dry powder inhaler; ICS, inhaled corticosteroid; pMDI, pressurized metered-dose inhaler.

(Figure 2). Results for disaggregated outcomes of the composite measures and percentages of patients with change in therapy are depicted in Table 4.

\section{Patients receiving an increased dose of ICS: step-up population}

As for the initiation population, baseline characteristics and measures that were statistically significantly different among the three cohorts (Tables 1 and 2) were included in the outcome analyses as potential confounding factors.

The median dose of ICS on the index date was lowest in the BAI cohort (500 vs $800 \mu \mathrm{g} /$ day in the other two cohorts), and proportionately more patients in the BAI cohort were prescribed a dose of $201-400 \mu \mathrm{g} / \mathrm{day}$, with the same interquartile range for dose in all three cohorts (Table 3 ). Spacers were prescribed to $12.8 \%, 1.5 \%$, and $0.8 \%$ of patients in pMDI, BAI, and DPI cohorts, respectively. As for the initiation population, while differences in ICS doses among the cohorts were statistically significant, the profile of doses received across the treatment cohorts was fairly similar, with the highest median ICS dose used in the pMDI cohort, which included proportionately more patients who received a dose $\geq 800 \mu \mathrm{g} /$ day.

Over the outcome year, the adjusted odds of asthma control was significantly greater in the BAI cohort than in the pMDI cohort, while the odds for the DPI cohort was not significantly different when adjusted for confounders (Figure 2). The adjusted rate ratios for severe exacerbations were significantly lower for both BAI and DPI cohorts (Figure 2).

There were no significant differences among cohorts in the odds for asthma control plus SABA use (Figure 2). Other secondary outcomes are summarized in Table 4.

\section{Discussion}

For the real-world primary care patients included in this database analysis, the odds of achieving our a priori definition of asthma control during the outcome year were significantly better for patients initiating ICS therapy via BAI or DPI compared with a pMDI, and for those receiving an ICS dose increase via BAI compared with a pMDI. The co-primary outcome measure, rate of severe exacerbations, 

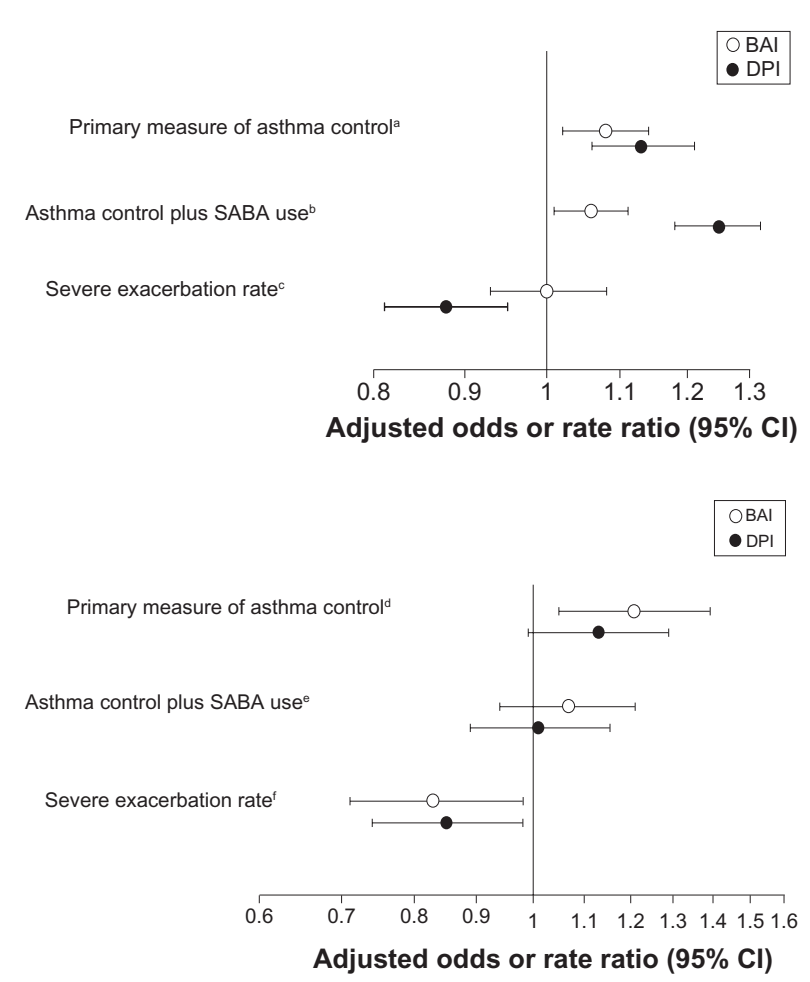

Figure 2 Odds ratios $(95 \% \mathrm{Cl})$ for achieving the composite measures of asthma control and rate ratio $(95 \% \mathrm{Cl})$ for severe exacerbations during the outcome year for patients who received a prescription for first ICS (top panel) or increased dose of ICS (bottom panel) using a BAI or DPI, with PMDI cohort as comparator.

Notes: Adjustments were made for following baseline parameters: aSex, age, GERD diagnosis, NSAIDs, acetaminophen, asthma consultations excluding oral steroids, antibiotics, oral steroid prescriptions, ICS dose at index date, year of index date; 'GERD diagnosis, NSAIDs, acetaminophen, asthma consultations excluding oral steroids, SABA dose, antibiotics, oral steroid prescriptions, hospital asthma definite, ICS dose at index date, year of index date; 'Age, NSAIDs, acetaminophen, asthma consultations excluding oral steroids, SABA dose, antibiotics, oral steroid prescriptions, hospital admissions, year of index date, ICS dose at index date; 'Sex, NSAIDs, acetaminophen, baseline SABA dose, antibiotics, oral steroid prescriptions, ICS dose at index date; ${ }^{e}$ Acetaminophen, asthma consultations excluding oral steroids, SABA dose, antibiotics, oral steroid prescriptions, ICS dose at index date; 'Sex, NSAIDs, asthma consultations excluding oral steroids, SABA dose, antibiotics, oral steroid prescriptions, average baseline ICS dose.

Abbreviations: BAl, breath-actuated inhaler; BMI, body mass index; DPI, dry powder inhaler; GERD, gastroesophageal reflux disease; ICS, inhaled corticosteroid; NSAIDs, nonsteroidal anti-inflammatory drugs; pMDI, pressurized metered-dose inhaler; SABA, short-acting $\beta 2$ agonist.

was significantly lower for those in the initiation population using a DPI and for those in the step-up population using a BAI or DPI, again as compared with a pMDI.

The goal of this study was to assess whether or not the asthma inhaler device is of material importance in the prescribing of ICS to patients in a real-world setting. The study results suggest that the inhaler device does in fact matter. Findings were generally consistent for BAIs and DPIs when compared with pMDIs and as prescribed for both initiation and step-up populations. Overall, the signal was stronger - in terms of the two co-primary outcome measures - with a DPI for patients initiating ICS and with a BAI for patients prescribed an increased dose of ICS.
While results of RCTs indicate little difference in the effectiveness of inhaler devices when used correctly and predominantly over the short-term, ${ }^{8,9}$ our findings suggest that real-world factors influence the effectiveness of these devices. Correct inhaler use is integral to the effectiveness of inhaled therapy, ${ }^{6,2426}$ and it is possible that correct use is easier to learn and maintain with BAIs and DPIs than with pMDIs. Other factors that could influence effectiveness of therapy include adherence to therapy, patient preferences, and physician practices and preferences. As reflected in the prescribing patterns captured by this study, pMDIs are the most commonly prescribed inhaler devices in the UK, perhaps in part because they have been available for longer. Thus, another possible explanation for the observed differences, purely speculative, is that patients prescribed a BAI or DPI rather than a pMDI constitute a particular subgroup of patients in the view of their physicians and thus are monitored more closely, with resultant better outcomes, than those prescribed the more common pMDIs.

The delivery of medication to the target airways from an inhaler device depends on proper preparation of the device coupled with correct inhalation technique, both of which are device-specific. The correct use of pMDIs requires actuation of the dose synchronized with an inhalation that is slow and deep; and the most common mistakes made with pMDIs are failure to coordinate actuation with inhalation and too rapid an inhalation. ${ }^{6,25,26}$ By contrast, dose emission from both BAIs and DPIs is actuated by the patient's inhalation, which should be slow and deep for a BAI and, for a DPI, sharp and forceful to aerosolize the dry powder. Some patients may not be able to achieve sufficient inspiratory flow to actuate certain types of DPI. ${ }^{27}$ Failure to exhale before actuation and to breath-hold after inhalation are mistakes common to all devices. ${ }^{10,12}$

Observational studies evaluating patients' abilities to use inhaler devices correctly show inconsistent results, with some reporting mistakes to be more common with pMDIs than DPIs and BAIs ${ }^{11,12}$ and others reporting similar prevalence of inhaler misuse with pMDIs and DPIs. ${ }^{13,28}$ While coordination of actuation and inhalation is a recognized challenge with pMDIs and many consider these to be a difficult device to use, ${ }^{6}$ all inhaler device types have specific requirements for proper preparation and use. Measures that can promote correct inhaler technique include provision of inhaler device training, repeat training with each revisit, and prescribing of the same type of inhaler device for both controller and reliever medications. ${ }^{25,26}$ Moreover, patients may have natural inspiratory patterns that accommodate one device better 
Table 4 Outcomes for patients initiating ICS or receiving an increased dose of ICS via pressurized metered-dose inhaler, breath-actuated inhaler, or dry powder inhaler

\begin{tabular}{|c|c|c|c|c|c|c|c|c|}
\hline & \multicolumn{4}{|c|}{ Initiation population $(\mathrm{N}=\mathbf{5 6 , 3 4 7 )}$} & \multicolumn{4}{|c|}{ Step-up population $(\mathbf{N}=9169)$} \\
\hline & $\begin{array}{l}\text { PMDI } \\
(N=39,746)\end{array}$ & $\begin{array}{l}\text { BAI } \\
(N=9809)\end{array}$ & $\begin{array}{l}\text { DPI } \\
(N=6792)\end{array}$ & $P$-value & $\begin{array}{l}\text { pMDI } \\
(\mathrm{N}=6245)\end{array}$ & $\begin{array}{l}\text { BAI } \\
(N=1388)\end{array}$ & $\begin{array}{l}\text { DPI } \\
(N=1536)\end{array}$ & $P$-value \\
\hline \multicolumn{9}{|l|}{ Asthma control status } \\
\hline $\begin{array}{l}\text { Primary measure of } \\
\text { asthma control }\end{array}$ & $29,96 \mid(75.4)$ & $7518(76.6)$ & $5307(78.1)$ & & $4237(67.8)$ & $1032(74.4)$ & II03 (7I.8) & \\
\hline $\begin{array}{l}\text { Asthma control plus } \\
\text { SABA use }\end{array}$ & $21,956(55.2)$ & $5605(57.1)$ & $4185(61.6)$ & & $2289(36.7)$ & $584(42.1)$ & $610(39.7)$ & \\
\hline \multicolumn{9}{|l|}{ Severe asthma exacerbations } \\
\hline 0 & $33,799(85.0)$ & $8366(85.3)$ & $5918(87.1)$ & & $4840(77.5)$ & II $44(82.4)$ & $1254(81.6)$ & \\
\hline 1 & 4407 (II.I) & I06I (I0.8) & $658(9.7)$ & & $850(13.6)$ & $166(12.0)$ & $180(\mid 1.7)$ & \\
\hline 2 & $978(2.5)$ & $255(2.6)$ & $|3|(1.9)$ & & $310(5.0)$ & $52(3.7)$ & $55(3.6)$ & \\
\hline$\geq 3$ & $562(1.4)$ & $127(1.3)$ & $85(1.3)$ & & $245(3.9)$ & $26(1.9)$ & $47(3.1)$ & \\
\hline \multicolumn{9}{|c|}{ Disaggregated outcomes of the composite measures: } \\
\hline$\geq \mathrm{I}$ oral corticosteroid course & $5938(14.9)$ & $1442(14.7)$ & $874(12.9)$ & 0.001 & $1400(22.4)$ & $242(17.4)$ & $282(18.4)$ & $<0.001$ \\
\hline$\geq I$ hospital attendance & $26(0.1)$ & $14(0.1)$ & $0(0)$ & 0.002 & $16(0.3)$ & $2(0.1)$ & $2(0.1)$ & 0.519 \\
\hline $\begin{array}{l}\geq \mid \text { course of antibiotics } \\
\text { for LRTI }\end{array}$ & $5079(12.8)$ & $1145(11.7)$ & $798(11.7)$ & 0.003 & $970(15.5)$ & $177(12.8)$ & $219(14.3)$ & 0.108 \\
\hline Mean SABA dose $>200 \mu g /$ day $^{a}$ & I I,832 (29.8) & $2779(28.3)$ & $1605(23.6)$ & $<0.001$ & $3152(50.5)$ & $66 \mathrm{I}(47.6)$ & $739(48.1)$ & 0.066 \\
\hline Change in or additional therapy & $550 I(13.8)$ & I583 (I6.I) & $1099(16.2)$ & $<0.001$ & $1693(27.1)$ & $318(22.9)$ & $444(28.9)$ & 0.001 \\
\hline Increase in ICS dose & $2908(7.3)$ & $959(9.8)$ & $602(8.9)$ & - & $320(5.1)$ & $75(5.4)$ & $104(6.8)$ & - \\
\hline $\begin{array}{l}\text { Use of additional Rx } \\
\text { for asthma }\end{array}$ & $3256(8.2)$ & $834(8.5)$ & $645(9.5)$ & - & I532 (24.5) & $266(19.2)$ & $386(25.1)$ & - \\
\hline
\end{tabular}

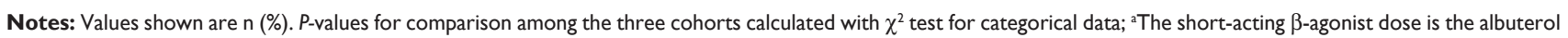
dose equivalent (standard dose in UK is $100 \mu \mathrm{g}$ ).

Abbreviations: BAI, breath-actuated inhaler; DPI, dry powder inhaler; ICS, inhaled corticosteroid; LRTI, lower respiratory tract infection; pMDI, pressurized metered-dose inhaler; SABA, short-acting $\beta 2$ agonist.

than another; this should be taken into consideration when choosing the inhaler type. ${ }^{25}$

The strengths of this study include the large numbers of patients with available data from a validated data source. The 12-month outcome period minimized the effect of seasonal changes and allowed us to record measurable differences in less frequent outcomes such as severe asthma exacerbations. Study outcome measures were chosen prospectively. Because of the large patient numbers, even baseline differences among inhaler cohorts that were small from a clinical perspective were often statistically significantly different. We included baseline characteristics that were statistically significantly different among the three cohorts as potential confounding factors in the outcome analyses.

Severe exacerbations were identified in the database using two parameters proposed by a recent joint task force of the American Thoracic Society and European Respiratory Society to define exacerbations, ${ }^{22}$ namely, unplanned or emergency care for asthma or a course of oral corticosteroid, both markers of poor asthma control. The primary measure of asthma control was a composite proxy that captured the absence in the database of recorded exacerbations or lower respiratory tract infection requiring antibiotics. The requirement for no recorded antibiotics for lower respiratory infection was based on the rationale that asthma exacerbations can be confused clinically for respiratory infection. ${ }^{29,30} \mathrm{~A}$ weakness of this proxy measure is evident in that three quarters (76\%) and over half (61\%) of patients in the initiation and step-up populations, respectively, met the primary asthma control definition during the baseline year before their health-care provider prescribed first ICS or an increased dose of ICS. Of course, the asthma control measure was not designed to supply information for a specific point in time, such as the date of the index prescription, but rather to summarize clinical information for a 1-year period.

The secondary composite measure was designed to add another aspect of asthma control to the primary outcome measure, namely, prescriptions for reliever therapy (SABA) as an indicator of asthma symptoms. The adjusted results for this measure significantly favored the BAI and DPI cohorts in the initiation but not the step-up population, as compared with the pMDI cohorts. We do not have a ready explanation for this difference between populations but note that SABA prescriptions are an imprecise measure of actual SABA use, ${ }^{22}$ 
as patients may obtain extra prescriptions to have reliever therapy readily available in different places frequented during the day.

Our study limitations include those inherent to any observational study using retrospective data. While results were adjusted for multiple potential confounding factors, there remains the possibility of confounding factors not accounted for, such as particle size of ICS and lung deposition profiles, as well as factors that cannot be adjusted for, such as health-care professional preference; this can compromise the internal validity of the study. Moreover, our study data were recorded when CFC propellants were still in common use; there may be issues related to the newer hydrofluoroalkane (HFA) propellants that are not captured by this study. Thus, we consider our study results to be hypothesis-generating and suggest that they be interpreted in conjunction with findings from RCTs, pragmatic trials, and other observational studies.

\section{Conclusion}

Results of this retrospective database study reflect real-world effectiveness of ICS via three different delivery devices and suggest that selection of inhaler device type has a bearing on clinical asthma outcomes. The odds of asthma control were mostly better, and severe exacerbation rates lower, for patients initiating or increasing ICS therapy via BAI or DPI rather than a pMDI. These differences among inhaler devices require closer evaluation in well-designed prospective trials.

\section{Acknowledgments}

We thank Martha Joseph and Linda Kemp for their work on the initial analyses.

Access to data from the General Practice Research Database was funded by Merck and Co., Inc., and the analysis was funded by Teva Pharmaceuticals Ltd.

\section{Disclosures}

David Price has consultant arrangements with Boehringer Ingelheim, GlaxoSmithKline, Merck, Mundipharma, Novartis, and Teva. He or his research team have received grants and support for research in respiratory disease from the following organizations in the last 5 years: UK National Health Service, Aerocrine, AstraZeneca, Boehringer Ingelheim, GlaxoSmithKline, Merck, Mundipharma, Novartis, Nycomed, Pfizer, and Teva. He has spoken for AstraZeneca, Boehringer Ingelheim, Chiesi, GlaxoSmithKline, Merck, Mundipharma,
Pfizer, and Teva. He has shares in AKL Ltd which produces phytopharmaceuticals. He is the sole owner of Research in Real Life Ltd.

John Haughney has received reimbursements for attending symposia, fees for speaking and organizing educational events, funds for research, or fees for consulting from AstraZeneca, Boehringer-Ingelheim, GlaxoSmithKline, Merck, Sharp and Dohme, Mundipharma, Novartis, Nycomed, Sanofi-Aventis, and Teva.

Elizabeth V Hillyer has done freelance writing work for Merck, Aerocrine, and Teva Sante (France).

Amanda J Lee receives payment for statistical consultancy from Research in Real Life Ltd.

Neil Barnes has lectured for or done consultancy for GlaxoSmithKline, AstraZeneca, Chiesi, Boehringer, Teva, and Nycomed and has received research support from GlaxoSmithKline, Novartis, and Schering-Plough.

All other authors report no conflicts of interest in this work.

\section{References}

1. Herland K, Akselsen JP, Skjonsberg OH, Bjermer L. How representative are clinical study patients with asthma or COPD for a larger "real life" population of patients with obstructive lung disease? Respir Med. 2005; 99:11-19.

2. Travers J, Marsh S, Williams M, et al. External validity of randomised controlled trials in asthma: to whom do the results of the trials apply? Thorax. 2007;62:219-223.

3. Van Spall HG, Toren A, Kiss A, Fowler RA. Eligibility criteria of randomized controlled trials published in high-impact general medical journals: a systematic sampling review. JAMA. 2007;297:1233-1240.

4. Rothwell PM. External validity of randomised controlled trials: "to whom do the results of this trial apply?" Lancet. 2005;365:82-93.

5. Rawlins MD. De Testimonio: On the evidence for decisions about the use of therapeutic interventions. Harveian Oration. Oct-2008 ed. London: Royal College of Physicians; 2008.

6. Virchow JC, Crompton GK, Dal Negro R, et al. Importance of inhaler devices in the management of airway disease. Respir Med. 2008; 102:10-19.

7. Brocklebank D, Ram F, Wright J, et al. Comparison of the effectiveness of inhaler devices in asthma and chronic obstructive airways disease: a systematic review of the literature. Health Technol Assess. 2001;5: $1-149$.

8. Brocklebank D, Wright J, Cates C. Systematic review of clinical effectiveness of pressurised metered dose inhalers versus other hand held inhaler devices for delivering corticosteroids in asthma. BMJ. 2001;323:896-900.

9. Dolovich MB, Ahrens RC, Hess DR, et al. Device selection and outcomes of aerosol therapy: evidence-based guidelines: American College of Chest Physicians/American College of Asthma, Allergy, and Immunology. Chest. 2005;127:335-371.

10. Lavorini F, Magnan A, Dubus JC, et al. Effect of incorrect use of dry powder inhalers on management of patients with asthma and COPD. Respir Med. 2008;102:593-604.

11. Lenney J, Innes JA, Crompton GK. Inappropriate inhaler use: assessment of use and patient preference of seven inhalation devices. EDICI. Respir Med. 2000;94:496-500. 
12. Molimard M, Raherison C, Lignot S, Depont F, Abouelfath A, Moore N. Assessment of handling of inhaler devices in real life: an observational study in 3811 patients in primary care. $J$ Aerosol Med. 2003;16:249-254.

13. Melani AS, Zanchetta D, Barbato N, et al. Inhalation technique and variables associated with misuse of conventional metered-dose inhalers and newer dry powder inhalers in experienced adults. Ann Allergy Asthma Immunol. 2004;93:439-446.

14. Giraud V, Roche N. Misuse of corticosteroid metered-dose inhaler is associated with decreased asthma stability. Eur Respir J. 2002;19: 246-251.

15. Price D, Thomas M, Mitchell G, Niziol C, Featherstone R. Improvement of asthma control with a breath-actuated pressurised metred dose inhaler (BAI): a prescribing claims study of 5556 patients using a traditional pressurised metred dose inhaler (MDI) or a breath-actuated device. Respir Med. 2003;97:12-19.

16. General Practice Research Database. http://www.gprd.com/home/ default.asp. Accessed January 7, 2011.

17. Jick SS, Kaye JA, Vasilakis-Scaramozza C, et al. Validity of the General Practice Research Database. Pharmacotherapy. 2003;23:686-689.

18. Soriano JB, Maier WC, Visick G, Pride NB. Validation of general practitioner-diagnosed COPD in the UK General Practice Research Database. Eur J Epidemiol. 2001;17:1075-1080.

19. Thomas M, von Ziegenweidt J, Lee AJ, Price D. High-dose inhaled corticosteroids versus add-on long-acting beta-agonists in asthma: an observational study. J Allergy Clin Immunol. 2009;123: 116-121, e10.

20. Price D, Martin RJ, Barnes N, et al. Prescribing practices and asthma control with hydrofluoroalkane-beclomethasone and fluticasone: a realworld observational study. J Allergy Clin Immunol. 2010;126:511-518. e1-e10.
21. Kemp L, Haughney J, Barnes N, et al. Cost-effectiveness analysis of corticosteroid inhaler devices in primary care asthma management: a real world observational study. ClinicoEconomics Outcomes Res. 2010; 2:75-85.

22. Reddel HK, Taylor DR, Bateman ED, et al. An official American Thoracic Society/European Respiratory Society statement: asthma control and exacerbations: standardizing endpoints for clinical asthma trials and clinical practice. Am J Respir Crit Care Med. 2009;180:59-99.

23. Charlson ME, Pompei P, Ales KL, MacKenzie CR. A new method of classifying prognostic comorbidity in longitudinal studies: development and validation. J Chronic Dis. 1987;40:373-383.

24. Cochrane MG, Bala MV, Downs KE, Mauskopf J, Ben-Joseph RH. Inhaled corticosteroids for asthma therapy: patient compliance, devices, and inhalation technique. Chest. 2000;117:542-550.

25. Haughney J, Price D, Barnes NC, Virchow JC, Roche N, Chrystyn H. Choosing inhaler devices for people with asthma: current knowledge and outstanding research needs. Respir Med. 2010;104:1237-1245.

26. Lavorini F, Levy ML, Corrigan C, Crompton G. The ADMIT series Issues in Inhalation Therapy. 6) Training tools for inhalation devices. Prim Care Respir J. 2010;19:335-341.

27. van der Palen J. Peak inspiratory flow through diskus and turbuhaler, measured by means of a peak inspiratory flow meter (In-Check DIAL). Respir Med. 2003;97:285-289.

28. Sestini P, Cappiello V, Aliani M, et al. Prescription bias and factors associated with improper use of inhalers. J Aerosol Med. 2006;19:127-136.

29. Kozyrskyj AL, Dahl ME, Ungar WJ, Becker AB, Law BJ. Antibiotic treatment of wheezing in children with asthma: what is the practice? Pediatrics. 2006;117:e1104-e1110.

30. Vanderweil SG, Tsai CL, Pelletier AJ, et al. Inappropriate use of antibiotics for acute asthma in United States emergency departments. Acad Emerg Med. 2008;15:736-743.

\section{Publish your work in this journal}

The Journal of Asthma and Allergy is an international, peer-reviewed open-access journal publishing original research, reports, editorials and commentaries on the following topics: Asthma; Pulmonary physiology; Asthma related clinical health; Clinical immunology and the immunological basis of disease; Pharmacological interventions and

\section{Dovepress}

new therapies. Issues of patient safety and quality of care will also be considered. The manuscript management system is completely online and includes a very quick and fair peer-review system, which is all easy to use. Visit http://www.dovepress.com/testimonials.php to read real quotes from published authors. 